\title{
A arte contemporánea en Galiza. Os seus centros, artistas e xestoras
}

\author{
Contemporary Art in Galicia: Artists, Art Galleries and \\ Women Who Manage Them
}

\author{
María Dolores ViLlaverde Solar \\ Universidade da Coruña \\ Departamento de Composición arquitectónica \\ Área de Historia da Arte \\ doviso@udc.es
}

[recibido 24/07/2014, aceptado 08/02/2015]

\section{RESUMO}

Este artigo pretende facer un resumo da situación artística en Galiza nas últimas décadas, dende os anos oitenta, etapa na que as mulleres non están xa, en teoría, excluídas do mundo artístico. Analízase a situación da muller na arte contemporánea e o papel das artistas, galeristas ou directoras de museos, etc., pois abórdanse décadas nas que a súa presenza na arte non se limita só a ser artista ou modelo. De igual forma e través dos seus traballos analízase se segue en vigor a arte feminista e se se ten en conta este tipo de arte ou non nos centros de arte contemporánea.

PALABRAS CHAVE: Muller, arte, xestión, museos, galerías.

\section{RESUMEN}

En este artículo pretende hacer un resumen de la situación artística en Galicia en las últimas décadas, desde los años ochenta, etapa en la que las mujeres no están, en teoría, excluidas del mundo artístico. Se analiza su situación en el arte contemporáneo y el papel que en él ocupan las artistas, pero también galeristas, directoras de museos, etc, pues se abordan décadas en las que su presencia en el arte no se limita únicamente a ser artista o modelo. De igual forma y través de sus trabajos se analiza si sigue en vigor el arte feminista y su presencia o no en los centros de arte contemporáneo.

PALABRAS CLAVE: Mujer, arte, gestión,museos, galerías.

\begin{abstract}
IThis paper will summarize art in Galicia from the eighties, a time in which women were not excluded from the artistic world, to the present moment. We shall analyse women's situation in contemporary art and the role they played. We shall study not only artists but also gallery owners and museum directors, as in this period women were not solely limited to being artists or models. Following this same line, we shall see if feminist art is still alive and present in contemporary art centres.
\end{abstract}

KEY WORDS: Women, art, management, museums, galleries.

VillaVerde Solar, Ma D. (2015): “A arte contemporánea en Galiza. Os seus centros, artistas e xestoras”, Madrygal (Madr.), 18, Núm. Especial: 603-608.

SUMARIO: 1. Introdución. 2. Percorrendo os centros de arte da comunidade galega. 3. Conclusións. 4. Referencias bibliográficas. 


\section{INTRODUCIÓN}

O presente artigo ten base en dous traballos de investigación iniciados en $2009^{1}$, onde se empezou a investigar a historia das mulleres nas artes, un dos ámbitos de estudo onde dende sempre, foi máis evidente a situación de inferioridade que as mulleres tiveron para poder acceder a estudos artísticos, ou para ser recoñecidas como creadoras, profesoras ou académicas, sufrindo unha discriminación e exclusión forzosa debido ás condicións sociopolíticas e culturais que lles impediron durante anos, décadas e séculos abandonar o ámbito privado e destacar nas artes.

Non se trata neste artigo de remontarse aos inicios da Historia da arte; máis ben ao contrario, imos achegarnos a décadas máis recentes, en concreto aos anos que van dende a década dos oitenta ata a actualidade. $O$ fío condutor serán os centros xeradores de arte contemporánea en Galicia. Tras a súa análise, observaremos que as mulleres dende un primeiro momento foron fundamentais para que a arte contemporánea chegase e se asentar na nosa comunidade autónoma, a cal tiña grandes carencias, pois ata 1985 estaba falta non só de tradición, senón tamén de lugares de exposición para a arte máis actual. As mulleres xogaron e xogan un papel protagonista, mais non só como artistas, senón tamén como galeristas, comisarias ou directoras de museos, fundacións e centros de arte contemporáneos.

\section{PERCORRENDO OS CENTROS DE} ARTE DA COMUNIDADE GALEGA

O percorrido iníciase nunha galería privada: a galería Trinta, que foi a primeira en atreverse cun proxecto arriscado nunha comunidade que carecía de calquera tipo de infraestruturas que o avalase. Dende un primeiro momento estivo vinculada ao centro Asunta Rodríguez, que nos seus inicios era asistente de dirección, e co tempo chegou a converterse en directora e propietaria. Trátase, por tanto, dunha galería que iniciou a súa andaina en tempos difíciles, de xeito moi humilde, e que chegou a converterse na galería máis distinguida no ámbito nacional e internacional. E a Asunta Rodríguez débeselle grande parte do éxito; por iso é de obriga iniciar este traballo con ela por ser capaz de arriscar nunha comunidade onde non se estilaba a arte contemporánea e nun mundo reservado aos varóns durante séculos.

En pleno 2014, a Trinta segue a funcionar e se decanta por relatos curtos reducindo o espazo para as exposicións á sala superior da galería ${ }^{2}$. Pola Trinta pasaron algúns dos artistas máis interesantes da arte contemporánea (Perejaume, Chema Madoz, Teo Soriano, Pamen Pereira, Anxel Huete, Juan Galdeano...). Hoxe, a Trinta continúa a ser un referente para Santiago, para os/as artistas e para outras galerías que tras ela foron chegando á cidade e ao resto da comunidade.

A segunda parada desde percorrido faise no Centro Galego de Arte Contemporánea ${ }^{3}$, que nace nos noventa case por necesidade de cubrir ese baleiro existente. Nos seus inicios, xunto ao primeiro director do centro (Antón Pulido) está Gloria Moure como directora artística. Axiña Pulido será substituído por Moure, que chega á dirección en 1996 e ostenta ese cargo ata 1998. A súa política expositiva pretende centrarse en artistas consagrados, sobre todo conceptuais dos anos sesenta e setenta con incursións na arte galega. Na súa etapa como directora o CGAC comeza a ser coñecido fóra da nosa comunidade, consolídase e conta

\footnotetext{
${ }^{1}$ Trátase de dous traballos de investigación do Mestrado en Investigación y docencia en Estudios Feministas, de Género y Ciudadanía, da Universidad Jaume I de Castellón, dirixidos pola Profesora Rosalía Torrent Esclapés: La discriminación y exclusión de las mujeres en la historia del arte occidental. Su manifestación en el arte gallego (curso 2009-2010) e Una aproximación a la situación de las mujeres a través de los centros generadores de arte contemporáneo en Galicia (curso 2010-2011).

${ }^{2}$ Empezou a súa andaina na Rúa Nova de Santiago de Compostela e agora está na rúa Virxe da Cerca.

${ }^{3}$ Véxase CGAC (2003).
} 
cunha boa programación, coidadas publicacións; porén, Gloria é destituída en febreiro de 1998, aínda que máis por cuestións políticas que pola súa capacidade ou xestión.

En canto á representación da muller no centro, cómpre dicir que dende o primeiro momento foi fundamental a súa presenza, pero chama a atención que queda un tanto no anonimato. Dende a súa fundación sempre houbo -e segue sendo así na actualidade- mulleres (máis que homes) no servizo pedagóxico, biblioteca, taller de restauración e gabinete de prensa; porén, como cabeza visible na dirección ou comisariado de mostras sempre estiveron en inferioridade con respecto aos homes, dato indicativo de que non todo está conquistado en materia de igualdade. As que están ao lado do director ocupan cargos de directoras artísticas ou directoras xerentes, e por ese feito quedan un tanto á súa sombra.

Se falamos de artistas, cabe dicir que nos dez primeiros anos (1993-2003) a presenza de mulleres que expoñen as súas creacións é imperceptible fronte aos homes. Tras iniciar a súa andaina coa pintora surrealista Maruja Mallo, decae o número de mostras de mulleres ata o ano 2000, se ben é verdade que, afortunadamente, a partir dese ano multiplícase o número de mulleres que expoñen no centro, tanto galegas como foráneas, e as cuestións de xénero empezan a interesar aos últimos directores do centro. CGAC dende os seus inicios contan coas máis importantes creadoras vinculadas a estas cuestións. Así aconteceu con Maruja Mallo (Viveiro, 1902 - Madrid 1995), seleccionada para inaugurar o dito centro por dúas razóns: por un lado, por tratarse dunha artista galega e, por outro, por ser unha das artistas que entendeu a vanguarda como un compromiso non só coa súa arte senón tamén coa vida.

Tras a de Maruja foron chegando as mostras de Tracey Moffatt, Esther Ferrer, Rebecca
Horn, Mona Hatoum... Sen esquecer que a primeira antolóxica en Galicia dedicada a Ana Mendieta tamén se realiza no CGAC e, tras o seu paso por Santiago, continuaría o seu itinerario por Barcelona, Düsseldorf, Miami ou Los Angeles.

A vida de Ana Mendieta ${ }^{4}$ (La Habana, 1948 Nueva York, 1985) estivo marcada pola traxedia. Iníciase co exilio de Cuba en 1961 e a separación dos seus pais. Os dous acontecementos marcárona e quedarán reflectidos na súa obra. Empeza a destacar como artista dende os primeiros anos setenta, pero morre moi cedo (1985) ficando truncada así a súa carreira. Nos últimos anos destacan as exposicións de Cristina García Rodero (Trastempo, que contou cunha colección de fotografías sobre Galicia) e a de Anna $\mathrm{M}^{\mathrm{a}}$ Maiolino, artista que nace en Italia, se educa en Venezuela e vive en Brasil. Formou parte do movemento antropofáxico brasileiro ${ }^{5}$, pero non se pode desvincular do feminismo, do land art ou da arte povera. Artista multidisciplinar, Ana Mendieta traballa fotografía, debuxo, escultura e vídeo.

Tras o CGAC foron emerxendo novos centros de arte e fundacións na comunidade galega que ampliaron a oferta de arte contemporánea e onde as mans femininas foron imprescindibles para o seu nacemento ou funcionamento.

O MARCO (Museo de Arte Contemporánea) da cidade de Vigo (Pontevedra) inaugúrase en 2001 con financiamento fundamentalmente municipal. Nos seus obxectivos é coincidente co CGAC; pretende ser un centro dinámico que non se limite a ser soamente un lugar de exposición. As exposicións temporais serán a base da programación e dedicaranse a dar a coñecer a produción artística recente nos distintos ámbitos creativos da comunidade autónoma galega, sen esquecer a arte nacional e internacional. Ao igual que xa acontecera no CGAC, no nacemento do MARCO o papel desempeñado polas mulleres foi esencial para

\footnotetext{
${ }^{4}$ Véxase Combalía (2006: 252-255).

${ }^{5}$ Este movemento nace con intención de que os artistas brasileiros devorasen as influencias extranxeiras e as converteran en algo novo.
} 
que a institución se afianzara. A primeira directora do MARCO, nos momentos en que botaba a andar, foi Carlota Álvarez Basso, que se encargou de dirixir o MARCO dende o seu nacemento ata o ano 2005. O actual director é Iñaki Martínez Antelo, quen ten a unha muller como adxunta, Agar Ledo, formada na Universidade de Santiago e no CGAC, así como en diferentes museos americanos e franceses. O MARCO non se caracteriza pola paridade dos artistas que alí expoñen, pero tampouco evita a presenza de creadoras femininas; máis ben todo o contrario: xa dende que se fundou as mulleres que se dedican á creación artística teñen un lugar reservado alí para presentar as súas propostas.

O MACUF (A Coruña) é un museo de titularidade privada que pertence ao grupo eléctrico Unión Fenosa. Conta cunha colección permanente e exhibe fondos adquiridos a través do certame bianual que organiza na Coruña dende 1989. A Primeira Mostra Unión Fenosa, nese mesmo ano, contou con Luis Caruncho como comisario, quen pasará a ser director do Museo sendo a directora xerente, a leonesa Carmen Fernández Rivera, que anteriormente traballara na xestión das exposicións itinerantes da Fundación Eugenio Granell e que na actualidade é a directora do MACUF.

Chegados aquí, cómpre mencionar outros centros que están tamén a realizar un labor importante de difusión e conservación da arte contemporánea. Son as fundacións, herdeiras dun legado artístico que deben conservar e xestionar. É necesario valorar as actuacións das mulleres que as xestionan, o seu labor de catalogación, conservación e difusión, as súas loitas contra administracións ou concellos e, o máis importante, un interese persoal por manter vivo non só o recordo á persoa querida, senón tamén a todas as súas creacións.
Destacan en Galicia a Fundación Granell, dirixida pola viúva e filla de Eugenio Granell, Amparo Segarra (sempre presente no padroado da Fundación Granell ata o seu falecemento en 2007) e a súa filla Natalia Fernández Granell, directora da Museo-Fundación centrado no Surrealismo. Conta cunha biblioteca especializada na dita vanguarda e tamén coa colección do artista surrealista Philip West ${ }^{6}$. A Fundación é un centro dinámico e a súa implicación na vida social de Santiago é cada vez maior. Tamén é destacable o interese polo tema na Fundación Granell, tanto dende a obra do propio Granell ${ }^{7}$ ou os collages da súa esposa Amparo, como a través das colectivas Pegados. Outro destacado exemplo é a Fundación Torre Pujales, dirixida por Cristina Torre Cervigón, viúva de Xulio Pujales, quen decide que a mellor forma de manter vivo o seu recordo é prestar un servizo á sociedade doando ao pobo galego a súa obra e colección privada a través desta institución, que inicia o seu percorrido en 2004. A Fundación Torre-Pujales, Museo de Arte Contemporáneo de Costa da morte ${ }^{8}$, nace ao falecer Julio Pujales, en Corme, un escenario de valor sentimental para o artista e a súa muller. Dende a súa fundación concede bolsas de residencias para artistas plásticos e, dende 2007, organiza cursos de verán á vez que expón e difunde a obra de Pujales.

Con cada muller mencionada -Asunta Rodríguez, Gloria Moure, Carlota Álvarez, Amparo Segarra, Cristina Torre, Carmen Rivera, Agar Ledo, etc. - faise evidente que dende o principio da década analizada (os 80), as mulleres tiveron un papel relevante e son en grande parte responsables de que a arte máis actual se achegase á comunidade galega e ao público en xeral, se aceptase e siga en vigor; pero sobre todo conseguiron afondar no tema da igualdade de dereitos, deberes, responsabilidades e oportunidades entre home e muller.

\footnotetext{
${ }^{6}$ Amigo personal de Eugenio Granell, doou a súa biblioteca á Fundación Granell. West foi un artista que, cando estaban triunfando o Minimalismo ou o Conceptual, volve sobre unha vanguarda como é o Surrealismo.

${ }^{7}$ Sobre este tema véxase García de Carpi (2005).

${ }^{8}$ Páxina web: http:// www.fmactorrepujales.com.
} 


\section{CONCLUSIÓNS}

Tras a elaboración da investigación, pódese concluír que no ano 2014 se atenuaron as diferenzas e/ou desigualdades entre home e muller e, polo menos en teoría, as mulleres temos as mesmas responsabilidades, oportunidades ou dereitos para acceder a determinados estudios, profesións e postos directivos. Atopámonos nun etapa, en que as mulleres non están xa silenciadas nin excluídas, teñen máis peso e, supostamente, máis facilidades para dedicarse profesionalmente á arte en todas as súas vertentes, dende as creadoras, ás docentes, académicas, comisarias de exposicións, directoras de museos e/ou centros de arte ou galeristas.

Asunta Rodríguez foi a primeira, pero todas con esforzo e os seus negocios son trascendentais para entender a evolución e difusión da arte contemporánea en Galiza. É de valorar sobre todo o seu atrevemento a se adentraren nun mundo tradicionalmente xestionado por homes, e a ser empresarias emprendedoras e xestoras. Porén, a pesar dos logros conseguidos, quedan aínda loitas por gañar e problemas por resolver, pois se ben xa non existe o illamento co que se tratou as creadoras durante séculos e as mulleres teñen acceso non só a estudios artísticos, tamén a ser docentes académicas, comisarias, directoras de centros de arte ou galeristas, no momento actual, cunha sociedade teoricamente igualitaria, realmente a utilización do termo igualdade non é de todo correcta e aínda se deben emendar algunhas deficiencias, como que non haxa compromiso de cota en ningún centro de arte a nivel de expositores/as, de comisarios/as nin de traballadores/as; que as mulleres que alcanzan postos directivos deban empezar, na súa maioría, de segundas, sendo un claro expoñente de que aínda as cousas non son igual de doadas para unha muller que para un home, ou que aínda teñan que xustificar as súas actuacións ou iniciativas por ser novas e mulleres... Todo isto é debido a que a discriminación da muller na historia da Arte segue existindo, aínda que se evidencia a través do chamado teito de cristal, un conxunto de factores que impiden a muller alcanzar ou consolidarse en metas máis altas na profesión que exerce.

\section{REFERENCIAS BIBLIOGRÁFICAS}

Alario Trigueros, M. Teresa (2008): Arte y feminismo. Donostia: Nerea.

ANDERSON, Bonnie y Judith ZINSSER (2007): Historia de las mujeres. Barcelona: Crítica.

Barbosa, Anna Mae (2008): “Artes visuais: exclusao da mulher e medo do feminismo", en Actas del congreso Mundos de Mujeres 08. La igualdad no es una utopia. Nuevas fronteras: avances y desafios. Madrid: Universidad Complutense, pp. 29-36.

BArro, David (2006): Sen xeración. Notas para unha historia da arte de Galicia. Santiago de Compostela: Auditorio de Galicia.

Castro Fernández, Xosé Antón (1999): “Os intentos de apertura e o debate en torno a abstracción”, Galicia Arte t. XVI. A Coruña: Hércules ediciones, pp. 84-147.

CGAC (2003): Dez anos do CGAC: 1993-2003. Santiago de Compostela: Xunta de Galicia.

Combalía, Victoria (2006): Amazonas con pincel. Barcelona: Ediciones Destino.

Fernández Granell, Natalia e Emmanuel GUIGON (2004): Los collages de Amparo Segarra. Santiago de Compostela: Fundación Granell.

GARCía De CARPI, Lucía (2005): La imagen de la mujer en la obra de Eugenio Granell. Córdoba: Fundación Provincial de Artes Plásticas Rafael Botí.

GonzÁlez-Alegre, Alberto (1997): “Atlántica”, en Galicia Terra Única. Galicia 1900-1990. Santiago de Compostela: Xunta de Galicia, pp. 345-352. 
JONES, Amelia (2007): “O legado da arte feminista", en A batalla dos xéneros. Santiago de Compostela: CGAC, pp. 51-66.

LÓPEZ FERnÁNDEZ CAO, Marian (2008): “Género y enseñanza del arte: visibilizar trayectorias de creación femenina", en Actas del congreso Mundos de Mujeres 08. La igualdad no es una utopía. Nuevas fronteras: avances y desafios. Madrid: Universidad Complutense, pp. 146-149.

MARINO, Paula (2000): “Atlántica: la renovación plástica gallega”, Espacio, tiempo y forma, serie VII/13, pp. 605-624.

MAYAYO, Patricia (2003): Historias de mujeres, historias del arte. Madrid: Ensayos de Arte Cátedra.

Penelas Figueiras, Severino (1993): “Os anos oitenta”, Galicia Arte. Arte contemporánea I. A Coruña: Hércules ediciones, vol. XVI, pp. 289-290.

Pollock, Griselda (2007): “O feminismo: un fenómeno mundial que chegou ata a Universidade. Reflexións sobre a influencia do feminismo no pensamento e a arte dende 1970", en A batalla dos xéneros. Santiago de Compostela: CGAC, pp. 89-104. 